\title{
Hybrid Optimization Approach for Energy Control in Electric Vehicle Controller for Regulation of Three-Phase Induction Motors
}

\author{
Abolfazl Mehbodniya, ${ }^{1}$ Parmod Kumar, ${ }^{2}$ Xie Changqing, ${ }^{3}$ Julian L Webber $\left(\mathbb{D},{ }^{4}\right.$ \\ Udit Mamodiya, ${ }^{5}$ Awal Halifa $\mathbb{D}^{6}{ }^{6}$ and Chennupalli Srinivasulu ${ }^{7}$ \\ ${ }^{1}$ Department of Electronics and Communication Engineering, Kuwait College of Science and Technology (KCST), \\ Kuwait City, Kuwait \\ ${ }^{2}$ Department of Electronics and Information Engineering, Jiangxi University of Engineering, Xinyu, Jiangxi, China \\ ${ }^{3}$ School of Energy and Electromechanical Engineering, Hunan University of Humanities, Science and Technology, Loudi, \\ Hunan, China \\ ${ }^{4}$ Graduate School of Engineering Science, Osaka University, Toyonaka, Osaka, Japan \\ ${ }^{5}$ Department of Electrical Engineering, Poornima College of Engineering, Jaipur, Rajasthan, India \\ ${ }^{6}$ Department of Electrical and Electronics Engineering, Tamale Technical University, Tamale, Ghana \\ ${ }^{7}$ Institute of Aeronautical Engineering, Hyderabad, Telangana, India \\ Correspondence should be addressed to Awal Halifa; ahalifa@tatu.edu.gh
}

Received 6 December 2021; Accepted 8 January 2022; Published 23 February 2022

Academic Editor: Vijay Kumar

Copyright ( $\odot 2022$ Abolfazl Mehbodniya et al. This is an open access article distributed under the Creative Commons Attribution License, which permits unrestricted use, distribution, and reproduction in any medium, provided the original work is properly cited.

\begin{abstract}
Three-phase induction motors are becoming increasingly popular for electric cars and industrial uses because of their improved efficiency and simplicity of production, among other things. Many enterprises and industries use induction motors in several rotating applications. However, it is a difficult talent to master when it comes to controlling the speed of an induction motor for various purposes. This study examines the performance of a three-phase induction motor using approaches such as field-oriented control and direct torque control. This work utilized the fractional order Darwinian particle swarm optimization (FODPSO) method in fuzzy methodology to optimize a motor's performance. Field-oriented control (FOC) and Direct torque control (DTC) methods are regulated by FODPSO, which is compared to standard FOC and DTC methods. MATLAB-Simulink was used to compare the outcomes of each system's simulation model to determine which one performed the best. The support vector machine-direct torque control (SVM-DTC) technology is famous for its rapid dynamic response and decreased torque ripples. Using torque and settling time and rising time reduction, the suggested technique is proved to be superior to the present way.
\end{abstract}

\section{Introduction}

There are a variety of approaches that may be used to control the torque of an induction motor. Because of their capacity to effectively follow torque and speed standards despite changes in load factors, control techniques such as direct torque control and field-oriented control have gained popularity [1]. Blaschke developed field-oriented control, also known as vector control, in 1970 and published his findings in 1971. This technique has the capability of manipulating the space vectors of voltage, current, and magnetic flux $[2,3]$ The fundamental benefit of this technology is that the flux and torque components maybe separated in the same manner as they can be separated in an independently stimulated direct current (DC) motor. Highspeed induction motor speed control simulation was reported by Maghfiroh et al. [4]. The simulation was based on direct current technology. The fuzzy-PID model was used to simulate the system under both loaded and unloaded circumstances. In this case, they were comparing fuzzy-PID 
with regular PID. The suggested approach uses 4.5 percent more energy in the no-load test than the existing technique. The energy consumption of fuzzy PID is 1.03 percent lower than that of classical PID in a load test [5]. A performance investigation of FOC and DTC for Permanent Magnet Synchronous Motor drives using the SVPWM technique was reported by Abassi et al. in 2015. One of the limitations of this method is that it necessitates the use of location information and mechanical sensors. Earlier this year, NanjibEIQuanjili, Aziz Derouich, and colleagues published a study of contemporary DTC augmentation techniques for induction motor drives.

The direct torque [6] approach simply creates the desired torque response of an induction motor by applying a constant voltage to the motor. Using space vector selection, the lookup table directs the regulated space vector selection for the stator flux and torque drive in this technique to stator flux and torque drive. When it comes to advantages, direct torque control trumps field-oriented control hands down. It is less vulnerable to external disturbances and more resistive to parameter changes and does not need the use of reference frame transformation [7] than indirect torque control. When compared to field-oriented control, the dynamic response is likewise rather excellent in this case. This work presents the results of the simulation of these two approaches using the fractional order Darwinian particle swarm optimization (FODPSO) with a fuzzy logic controller (FODPSO-FLC) $[8,9]$, and the findings are compared to those obtained using a three-phase induction motor.

However, various studies on DTC and FOC, as well as the use of other kinds of controllers to enhance the performance of those motor control systems, have been published in recent years. The fact that all of those reports and studies were solely focused on performance comparisons, which presume that everything is going smoothly, which is not always the case, presents another concern. As a consequence, two power quality concerns have been included in these comparative studies: voltage sag and brief interruption $[10,11]$. On the one hand, a theoretical comparison of DTC [11] and other motor drive techniques was published, outlining the fundamental principles of DC drive [12], flux vector, scalar control, and DC drive. On the other hand, a theoretical comparison of DTC and other motor drive techniques was published, outlining the fundamental principles of DC drive. On the other hand, DTC and FOC have been the subject of much research, both separately and in conjunction with the use of other kinds of controllers to enhance the performance of those motor control systems.

Using topology modification, such as the addition of gears for the components or the use of a gearbox with a limited number of ratios, Kabalan et al. [13] investigated the potential for efficiency improvement of a simple seriesparallel hybrid electric vehicle powertrain using a simple series-parallel hybrid electric vehicle powertrain. The data revealed that the efficiency of one variation decreased while the efficiency of another variant increased, with a fuel consumption result that was equivalent to that of the conventional Toyota Hybrid System. Vora et al. [14] developed a powertrain simulation and battery deterioration which were both integrated into the model-based framework. The development of models for predicting fuel usage, electrical energy consumption, and battery replacement is now underway. These findings were paired with economic assumptions in order to allow for further investigation of a more expansive design space in order to deliver greater insights to vehicle integrators, component makers, and purchasers of hybrid and electric vehicles (HEVs). For the first time, Lei et al. [15] presented an innovative strategy for constructing a battery-electric powertrain that reduces energy usage while preserving vehicle performance and comfort. Requirements for power performance, energy usage, and other factors are also reduced. Vehicle-specific characteristics such as ride comfort and handling were developed. Following that, the resulting requirements were applied to the subsystem level, where torque outputs, motor efficiency, and other parameters were taken into consideration. The equivalent criteria were vehicle weight and vehicle length. At the subsystem level, a multiobjective global optimization was carried out, and a restricted-energy technique was used to reduce energy consumption. It was suggested that the vehicle level be used. The final solution featured a lightweight-to-heavyweight ratio of 93.5 percent and was very compact, so $92 \%$ motor efficiency was achieved.

For the last point, past work has concentrated on the parallels between FOC and DTC by reexamining the underlying principles of both and studying ways to merge the two to provide a control algorithm that is both more accurate and quicker. Therefore, this research was compared to the previous studies, with a greater number of comparable parameters being included in the comparison. Specifically, the proposed work explains the operation of FOC in section 2 , the operation of DTC in section 3, the FODPSO approach for fuzzy control in section 4 , simulation, the result, and a comparison of the various techniques in section 5 , and the conclusion in section 6 .

\section{Field-Oriented Control}

The FOC technique makes use of orthogonal transformation, in which $a-b-c$ coordinates are transformed to $\mathrm{dq} 0$ coordinates, as seen in the diagram. This will allow for independent control utilizing direct axis or quadrature axis currents since the torque and flux components will no longer be connected together. PI controllers are capable of regulating the output voltage, which limits the reaction time of the torque controller under transient conditions. The components of the FOC system are an IGBT-based VSI inverter, an induction motor, an IGBT-based controller, and a current control-based PWM block. In this comparison, the rotor speed $(r)$ is compared with the reference speed $\left(r^{*}\right)$, and the difference in speed is supplied into a PI controller. A limiter is a device that restricts the amount of reference torque $\left(\mathrm{Tk}^{*}\right)$ produced by the PI controller. The reference current for the quadrature axis component of current $\left(\mathrm{Iq}^{*}\right)$ is formed by limiting the value of Tref* to a reasonable value. In a similar vein, the direct axis component of current is dictated by the rotor speed of the electric motor. The combination of the quadrature axis and direct axis 
components of currents results in the generation of threephase reference currents. In the next step, the measured three-phase winding current value is compared to the threephase reference current value, with the resulting error being passed back to the PWM block. This equation is then used to create the switching signal, which is subsequently used.

$$
\begin{aligned}
i_{d s} & =\left(\Psi_{d s}-\frac{L_{m}}{L_{r}} \Psi_{d r}\right) \frac{1}{\sigma L_{s}}, \\
i_{q s} & =\left(\Psi_{q s}-\frac{L_{m}}{L_{r}} \Psi_{q r}\right) \frac{1}{\sigma L_{s}}, \\
i_{d r} & =\left(\Psi_{d r}-\frac{L_{m}}{L_{r}} \Psi_{d s}\right) \frac{1}{\sigma L_{r}}, \\
i_{q r} & =\left(\Psi_{q r}-\frac{L_{m}}{L_{s}} \Psi_{q s}\right) \frac{1}{\sigma L_{r}}, \\
\text { Here } \sigma & =1-\frac{L_{m}^{2}}{L_{s} L_{r}}, \\
T_{e} & =\frac{3}{2}\left(\frac{P}{2}\right)\left(\Psi_{d r} i_{q s}-\Psi_{q r} i_{d s}\right), \\
\Psi_{r} & =\sqrt{\Psi_{d r}^{2}+\Psi_{q r}^{2}}, \\
\tan & -1\left(\frac{\Psi_{q r}}{\Psi_{d r}}\right) .
\end{aligned}
$$

\section{FODPSO-FLC-Based FOC}

The power supply circuit, three-phase diode rectifier, speed controller, IGBT-based VSI inverter, feedback optimization circuit, and optimization circuit are all shown in the block diagram in Figure 1. The fundamental concept of a threephase induction motor is to transform three-phase electrical energy into mechanical energy $[16,17]$. The magnetic field produced by the stator is caused by the alternating current power provided to it. The rotor of a synchronous motor, on the other hand, spins in reaction to the magnetic field created by the stator of the motor. Because of the rotating magnetic flux in the rotor winding, current may be induced in the secondary winding of the transformer, and this current is then used to power the transformer. The controller that has been proposed is a mix of the FODPSO and the FLC. FODPSO is an acronym for the fractional order Darwinian particle swarm optimization [18]. Optimization is a technique that is used to create the greatest potential output value while minimising costs. Optimization is used to determine the difference between the rotor and reference speeds, and the error speed is sent to the PI (Proportional Integral) controller.

FLC is a fuzzy logic controller. The fuzzy logic controller is divided into three sections:

(i) Fuzzification
(ii) Inference system
(iii) Defuzzification

Table 1 represents the fuzzy set for input error function.

3.1. Direct Torque Control. The direct torque control drive is composed of a torque controller, a speed controller, and an IGBT-based variable speed inverter (VSI). It is possible to create an error signal when the reference speed and the rotor speed are compared [19]. In order to compensate for the speed mistake, the PI controller creates reference torque $\left(\mathrm{Tk}^{*}\right)$. After that, a torque limiter utilized to keep the torque under control. It is possible to determine the torque inaccuracy by comparing the restricted torque reference (Tref) with the actual torque recorded by the machine, and the result is presented in Table 1 . The reference speed of the motor is computed by combining the estimated stator flux of the motor with the expected rotor speed flux $(r)$. The switching vectors for the VSI are determined by the errors in flux and torque [20]. The amount of torque linked to the rotor flux and the stator flux is as follows:

$$
T_{e}=\frac{3}{2}\left(\frac{P}{2}\right) \frac{L_{m}}{L_{r} L_{s}^{\prime}}\left|\Psi_{r} \| \Psi_{s}\right| \operatorname{Sin} \gamma .
$$

The stator flux and the rotor flux in complex form can be represented as

$$
\begin{aligned}
& \bar{\Psi}_{s}=L_{s} \bar{I}_{s}+L_{m} \bar{I}_{r}, \\
& \bar{\Psi}_{r}=L_{r} \bar{I}_{r}+L_{m} \bar{I}_{s} .
\end{aligned}
$$

The estimated stator flux and torque values are compared to the command stator flux and torque values, and the error is processed using a hysteresis band controller.

$$
\begin{aligned}
& H_{\Psi}=1 \quad \text { for } E_{\Psi}>+\mathrm{HB}_{\Psi}, \\
& H_{\Psi}=-1 \text { for } E_{\Psi}<-\mathrm{HB}_{\Psi} .
\end{aligned}
$$

Here, the flux controller will have a hysteresis bandwidth of $2 \mathrm{HB}_{\Psi}$ and rotates in anticlockwise direction. The torque control loop has three levels of digital output, which are related as follows:

$$
\begin{aligned}
& H_{T e}=1 \quad \text { for } E_{T e}>+\mathrm{HB}_{T e}, \\
& H_{T e}=-1 \text { for } E_{T e}<-\mathrm{HB}_{T e}, \\
& H_{T e}=0 \text { for }-\mathrm{HB}_{T e}<E_{T e}<+\mathrm{HB}_{T e} .
\end{aligned}
$$

3.2. FODPSO-FLC-Based DTC. The FODPSO-FLC technique combines the fuzzy logic controller and fractional order Darwinian particle swarm optimization techniques [21]. Figure 2 depicts the FODPSO-FLC-based DTC block diagram. The torque error, which compares the reference torque to the rotor torque, is the first stage. Through the FODPSO optimization technique, the estimated error is fed into the controller. 


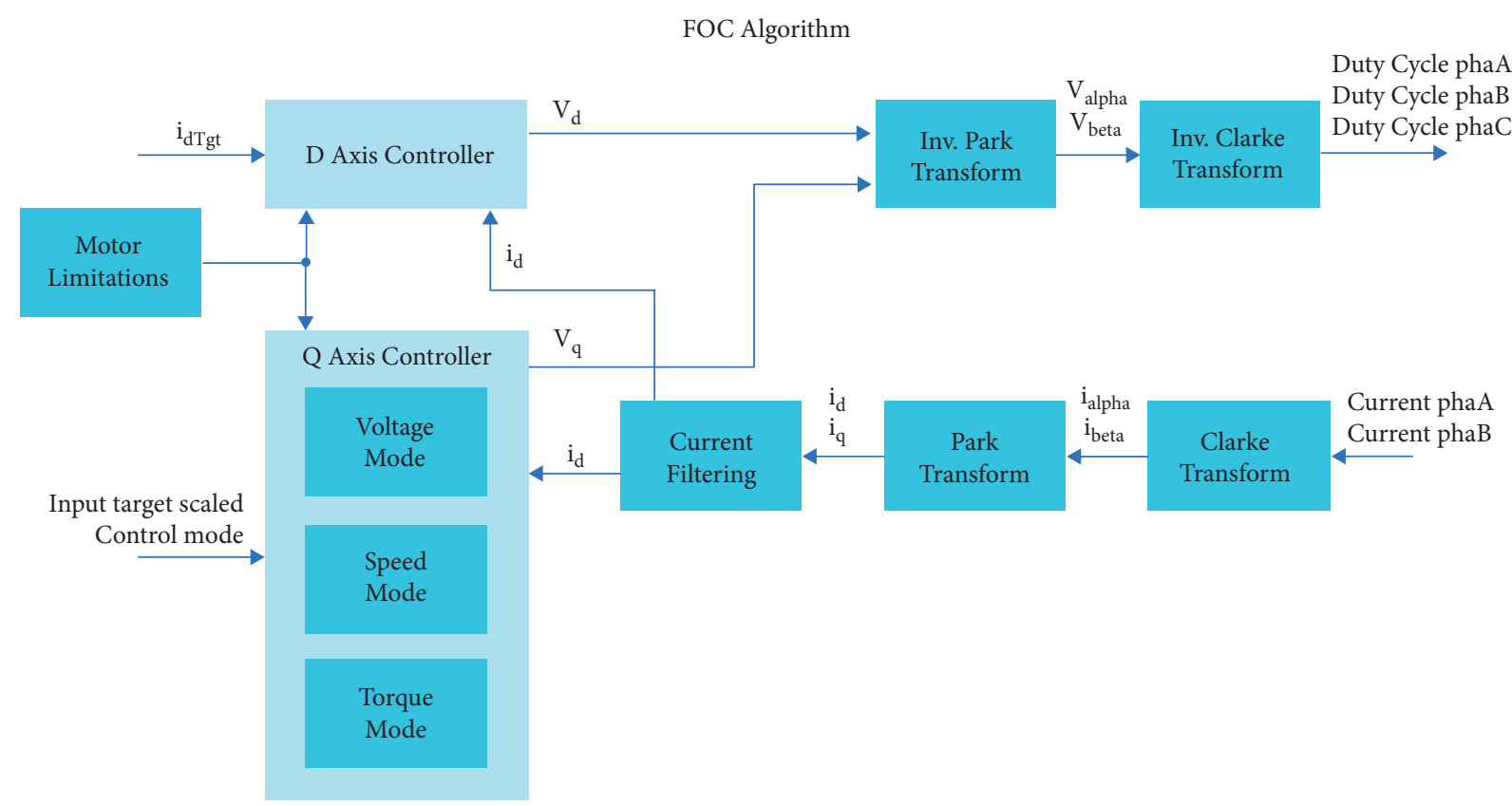

Figure 1: FODPSO-FLC-based FOC.

TABLE 1: Fuzzy set for input error.

\begin{tabular}{|c|c|c|c|}
\hline Fuzzy set & Membership function & Range & Set description \\
\hline NL & Trapezoidal & $\begin{array}{l}-1.0 \text { to }-1.0 \\
-1.0 \text { to }-0.8 \\
-0.8 \text { to }-0.5 \\
\end{array}$ & Speed error is high in the negative direction \\
\hline NM & Triangular & $\begin{array}{l}-0.8 \text { to }-0.5 \\
-0.5 \text { to }-0.2\end{array}$ & Speed error is medium in negative direction \\
\hline $\mathrm{ZE}$ & Triangular & $\begin{array}{c}-0.2 \text { to } 0 \\
0 \text { to } 0.2 \\
\end{array}$ & Speed error is around zero \\
\hline $\mathrm{PM}$ & Triangular & $\begin{array}{l}0.2 \text { to } 0.5 \\
0.5 \text { to } 0.8\end{array}$ & Speed error is medium in positive direction \\
\hline $\mathrm{PL}$ & Trapezoidal & $\begin{array}{c}0.5 \text { to } 0.8 \\
0.8 \text { to } 1 \\
1 \text { to } 1 \\
\end{array}$ & Speed error is large in positive direction \\
\hline NS & Triangular & $\begin{array}{c}-0.5 \text { to }-0.2 \\
-0.2 \text { to } 0\end{array}$ & Speed error is smaller in negative direction \\
\hline PS & Triangular & $\begin{array}{c}0 \text { to } 2 \\
0.2 \text { to } 0.5\end{array}$ & Speed error is small in the positive direction \\
\hline
\end{tabular}

\section{Simulation Results}

The goal function may be calculated by using the fitness function as a starting point. The primary objective is to monitor the highest amount of wind power while keeping inaccuracy to a bare minimum during turbine mechanical power generation [22]. The FODPSO method, which is inspired by the PSO algorithm, is shown in Figure 3, and its flow chart is given in Figure 4. It is used to acquire the required minimised and maximised values using an optimization strategy such as the FODPSO algorithm. Computer algorithms like particle swarm optimization (PSO) [23] may theoretically improve a problem by repeatedly trying to execute a feasible solution.

Candidate solutions are referred to as particles in the PSO approach, and each particle travels over the search space in pursuit of the greatest potential answer. In contrast to the particle [24], the swarm retains its global best position in the search space for each step, whereas the particle keeps its unique best position in the search space for each step. The calculating process of the PSO method traps particles around the suboptimal solution in the search space, resulting in a clogged search space. As a result, the issue was solved by utilizing the Darwinian PSO method of optimization (DPSO). The PSO is based on Darwinian evolution. This DPSO makes use of a multisimultaneous parallel PSO approach, with each swarm in the search space having its own swarm. However, there is a drawback to this approach: if the search results in a substandard result, the search in that location is simply discarded, and a new area is investigated instead. For this reason, DPSO has a problem with the stagnation that causes it to shorten the lifespan of swimming 


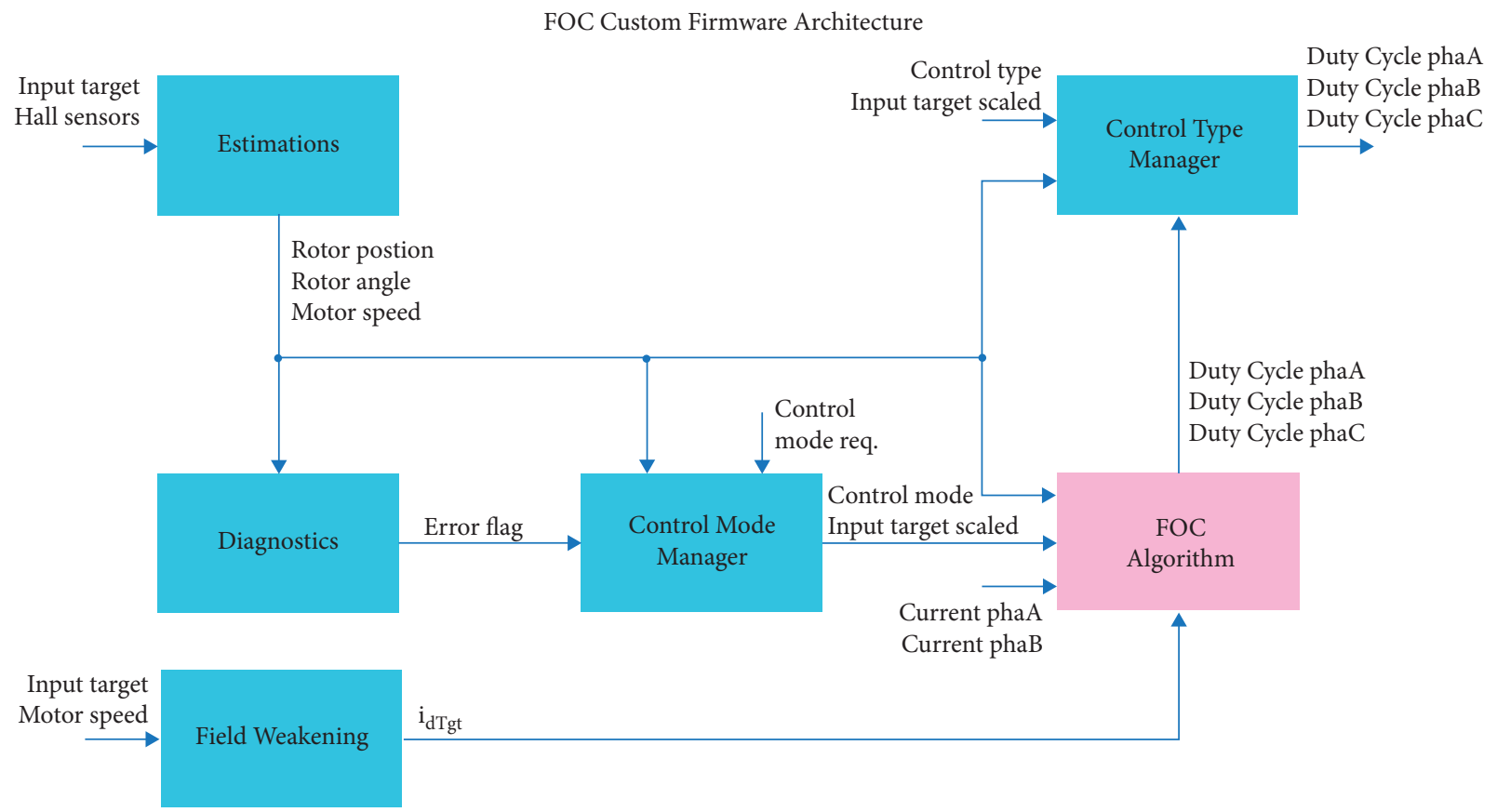

Figure 2: FODPSO-FLC-based DTC.

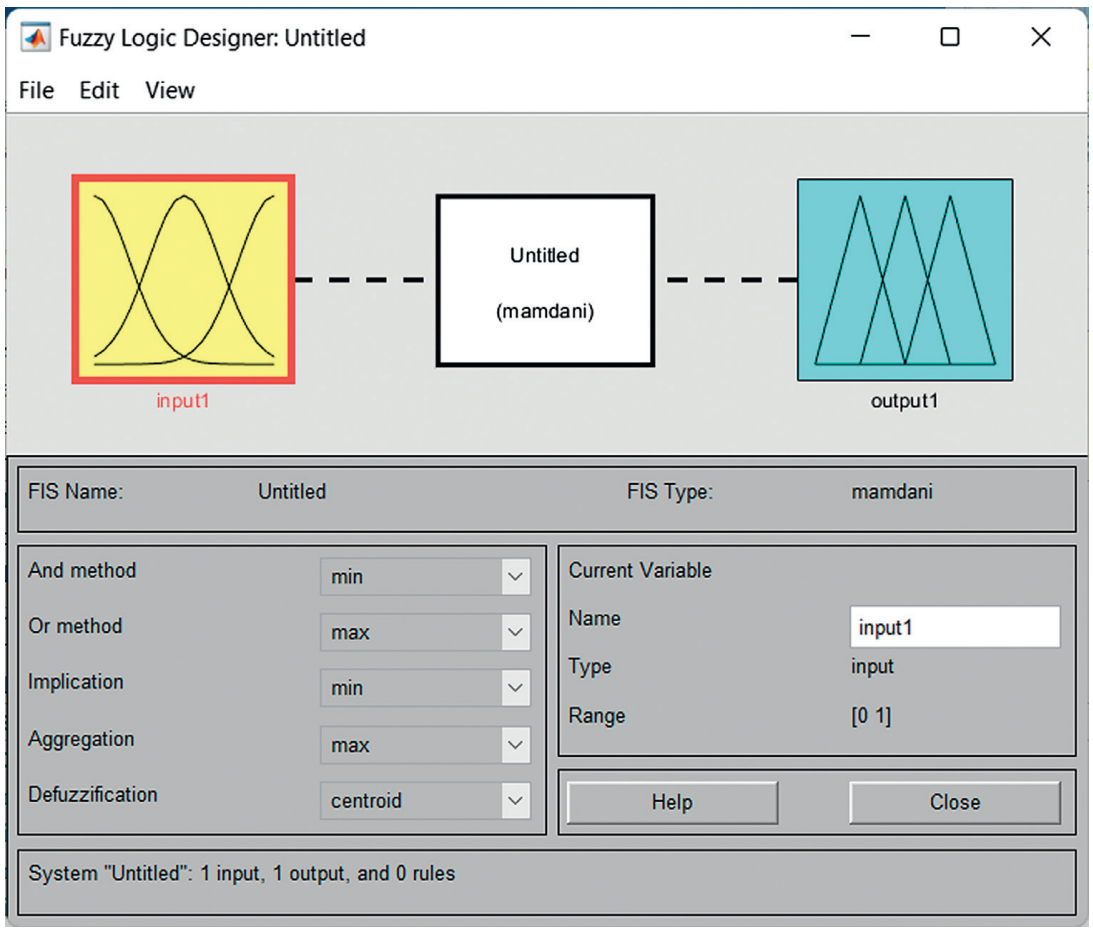

Figure 3: Fuzzy optimization by FODPSO technique.

particles and erase them from the search area automatically. As a consequence, reaching a point of convergence takes an inordinate amount of time. DPSO was proposed as a method of addressing the complexity of DPSO while also controlling its convergence rate. The DPSO has submitted a proposal for fractional ordering. Particle trajectories and dynamic events benefit from this fractional order since it needs an infinite number of requirements to be satisfied [25].
Table 2 represents the electrical parameters of induction motor and the different parametric values.

MATLAB-Simulink is used to model a sensor-less FOC of an induction motor drive for a $200 \mathrm{HP}$ AC motor. The model-referencing adaptive system approach is used to calculate the motor speed from terminal voltages and currents. As a result, the speed sensor is no longer functional. The induction motor's parameters are listed in Table 2. 


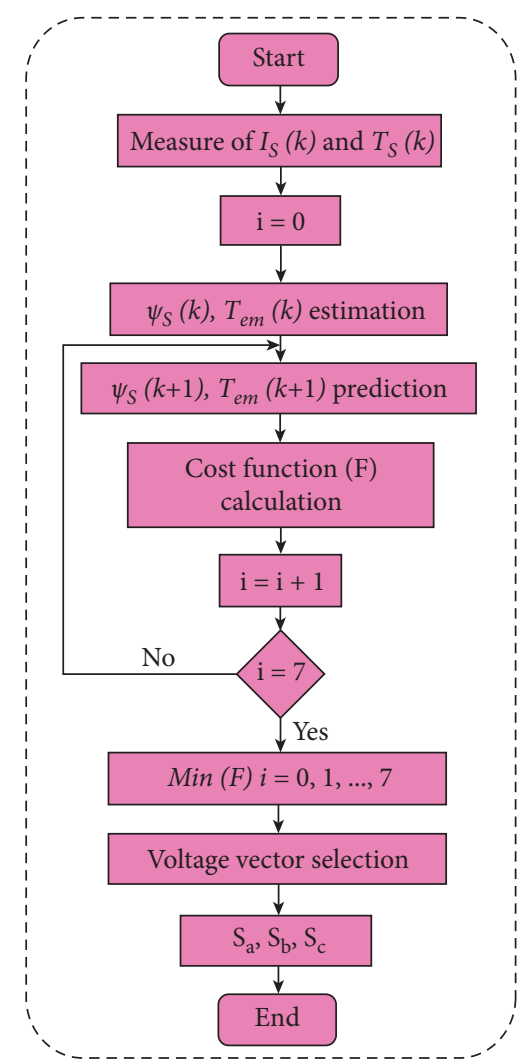

FIGURE 4: Flow chart for FODPSO based on the fuzzy technique.

TABLE 2: Electrical parameters of induction motor.

\begin{tabular}{lc}
\hline Different parameters & Value \\
\hline Rated power & $149.2 \mathrm{~kW}$ \\
Rated voltage & $440 \mathrm{~V}$ \\
Stator resistance & $15 \mathrm{~m} \Omega$ \\
Rated speed & $500 \mathrm{RPM}$ \\
Stator inductance & $0.3 \mathrm{mH}$ \\
Horse power & $200 \mathrm{HP}$ \\
Rotor resistance & $9 \mathrm{~m} \Omega$ \\
Rotor inertia & $3 \mathrm{kgm}$ \\
Rotor inductance & $0.3 \mathrm{mH}$ \\
Pole pairs & 2 \\
\hline
\end{tabular}

This is accomplished by driving the induction motor using a voltage source inverter, which is constructed from a three-phase bridge rectifier of the Simulink model of FOCbased FODPSO, as shown in Figure 5. The flux and torque references for the FOC controller are generated by a PI controller that is included in the speed control loop. When the FOC controller calculates the flux and torque references for the motor, a three-phase current regulator is used to provide the motor with the three reference motor line currents.

This discretized FOC system has a step time of 2 us and has been discretized. The speed controller employs a 140second sample period to simulate the control device, while the DTC controller uses a 20-second sampling time to emulate the control device. The switching frequency of the inverter has been set at $5 \mathrm{kHz}$. This is shown in Figure 6 .
When the forward operating mode is activated, the reference speed is set to $500 \mathrm{rpm}$ at time $0.5 \mathrm{~s}$, and when the forward operating mode is deactivated at time $2 \mathrm{~s}$, the reference speed is reduced to $0 \mathrm{rpm}$.

Similarly, at $t=1 \mathrm{~s}$, the full load torque, i.e., $100 \mathrm{Nm}$ is applied to the motor shaft and torque is brought back to $0 \mathrm{Nm}$ at $2.5 \mathrm{~s}$, which is shown in Figure 7.

At $t=0.5 \mathrm{~s}$, as the reference speed set point is increased to $500 \mathrm{rpm}$, at this instant, the motor speed starts to accelerate and settles at $500 \mathrm{rpm}$ after $0.33 \mathrm{~s}$. Therefore, the reference speed and rotor speed of a three-phase induction motor using the FOC method are shown in Figure 8.

At $2 \mathrm{~s}$, the reference speed is reduced to $0 \mathrm{rpm}$, causing the rotor speed to drop to $0 \mathrm{rpm}$ in $0.33 \mathrm{~s}$ by exactly following the deceleration ramp and the motor speed to stabilize at $0 \mathrm{rpm}$ shortly after. The complete load torque is given to the motor shaft at $t=1 \mathrm{~s}$, yet the motor speed continues to ramp up to its final value during this interval. When the motor hits $500 \mathrm{rpm}$ and the speed ramping is completed, the electromagnetic torque reaches its maximum $(500 \mathrm{Nm})$ and then stabilises. It is also worth noticing that the speed curve exceeds $500 \mathrm{rpm}$ at $0.83 \mathrm{~s}$ before settling at $500 \mathrm{rpm}$ at $1 \mathrm{~s}$. The peak overshoot in the speed curve of three-phase induction motor using the FOC method is shown in Figure 9.

When the stator current curve is examined, which is shown in Figure 10, it reveals a starting current of $1540 \mathrm{~A}$ and a negative peak current of $-3050 \mathrm{~A}$, but this peak settles at $0.04 \mathrm{~s}$ to a magnitude of $100 \mathrm{~A}$ at no load.

It is also seen that when the machine starts to accelerate at $0.5 \mathrm{~s}$ and the magnitude of current increases to $250 \mathrm{~A}$, the extent drops to $100 \mathrm{~A}$ at 0.85 . When reference speed is either accelerated or decelerated, the magnitude of current increases, but if the speed is maintained constant, the stator current oscillates around $100 \mathrm{~A}$, and this is shown in Figure 11.

During the interval from $0.5 \mathrm{~s}$ to $0.83 \mathrm{~s}$, the electromagnetic torque increases to $500 \mathrm{Nm}$. Similarly, when load torque is applied at $1 \mathrm{~s}$, the electromagnetic toque is maintained at $120 \mathrm{Nm}$. During deceleration, the load torque stabilizes at $-400 \mathrm{Nm}$. During the interval from $2 \mathrm{~s}$ to $2.83 \mathrm{~s}$, the electromagnetic toque oscillates around $110 \mathrm{Nm}$.

Figure 12 depicts a MATLAB-Simulink simulation of direct torque management using space vector pulse width modulation for a three-phase induction motor, and its model is shown in Figure 13. A voltage source inverter powers a three-phase induction motor in the system. This method uses fixed frequency control instead of variable frequency control. The torque and flux characteristics required for the direct torque control block are estimated by the PI controller that is positioned in the speed control loop. A reference voltage vector is created by comparing the estimated flux and motor torque values to the reference values. With a $2 \mu$ s time step, the DTC system was discretized. The speed controller employs a 100 us sampling interval to represent the system, whereas the vector controller uses a $20 \mu$ s sample period.

At $0.5 \mathrm{~s}$, the motor starts to accelerate and achieves a peak overshoot of $506 \mathrm{rpm}$ at $1.05 \mathrm{~s}$ and settles to $500 \mathrm{rpm}$ at $1.25 \mathrm{~s}$. The reference rotor speed and the peak overshoot of 


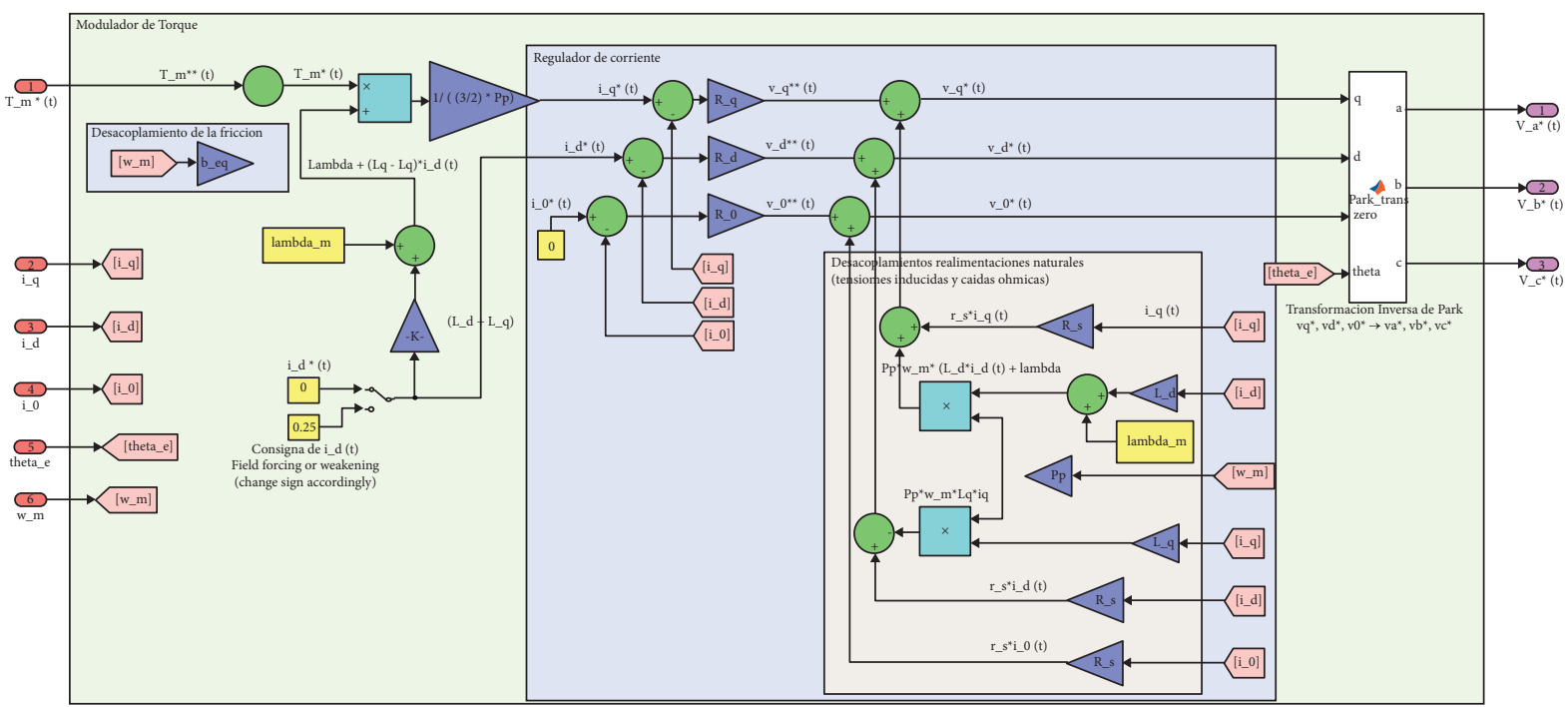

Figure 5: Simulink model of FOC-based FODPSO.

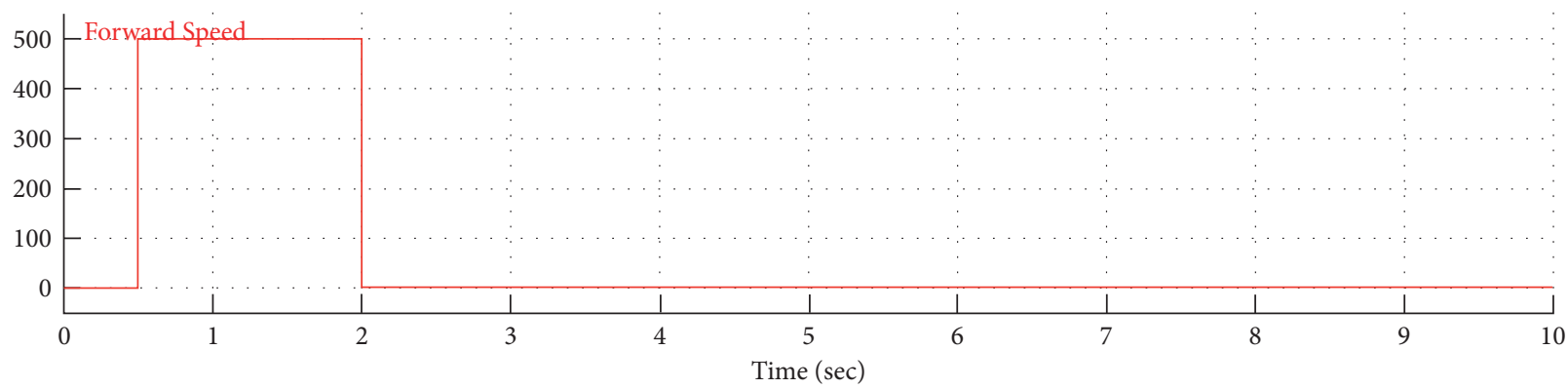

Figure 6: Reference speed for a motor operated in a forward direction.

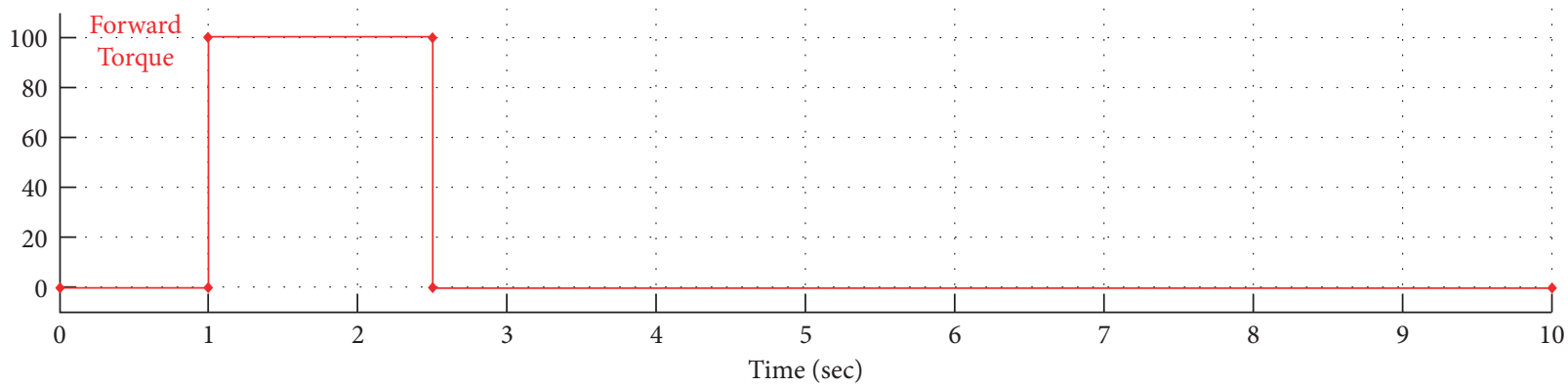

Figure 7: Reference input torque applied to the motor shaft.

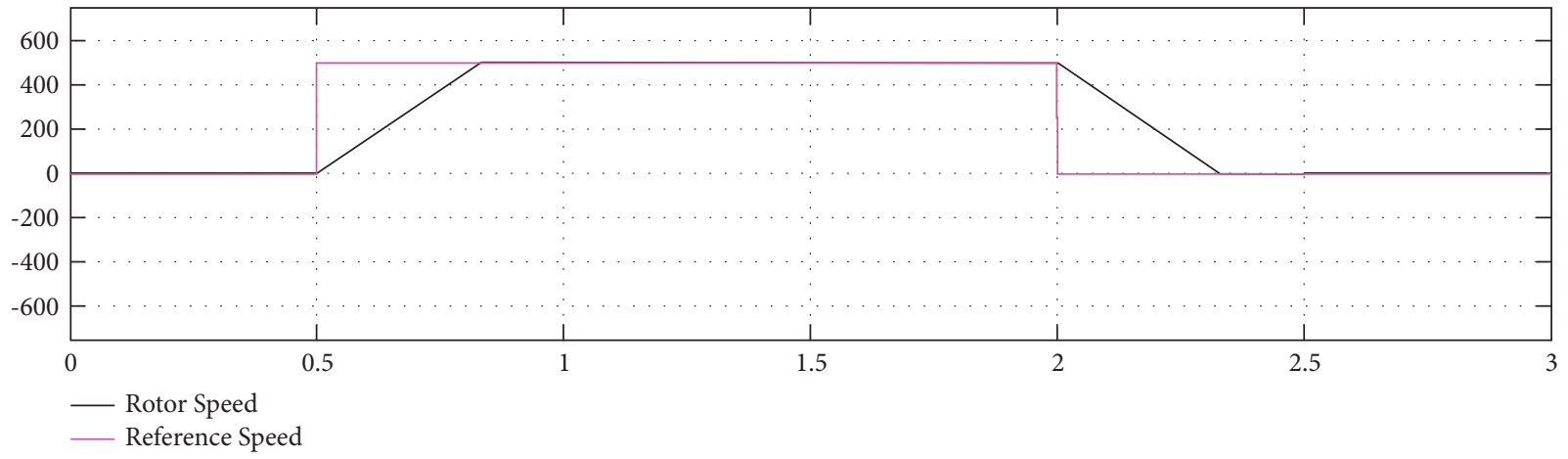

FIGURE 8: Reference speed and rotor speed of a three-phase induction motor using the FOC method. 


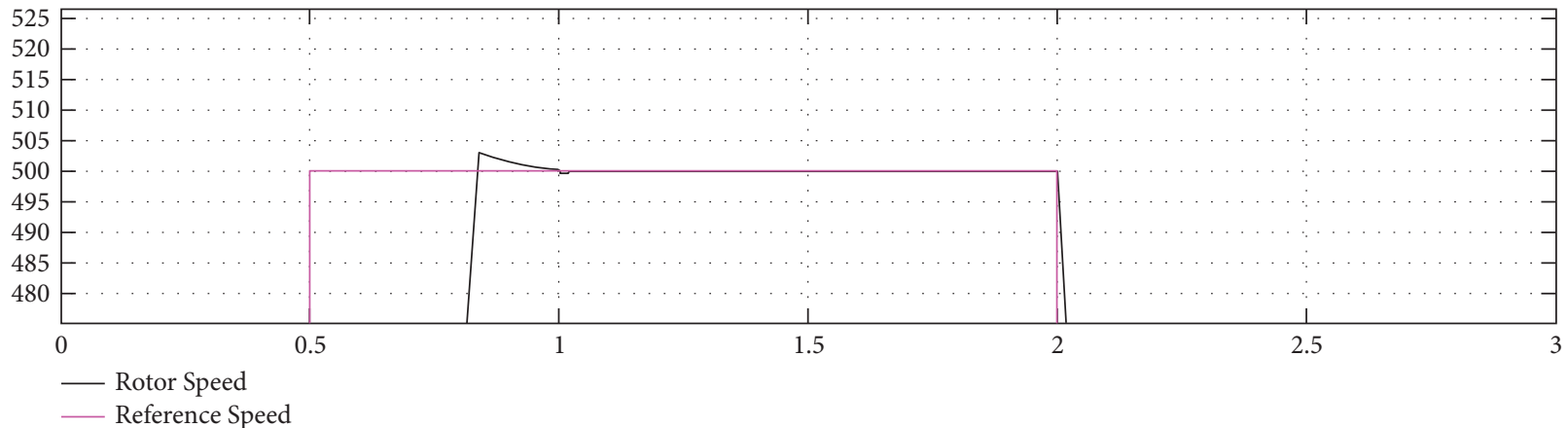

FIGURE 9: Peak overshoot in the speed curve of three-phase induction motor using the FOC method.

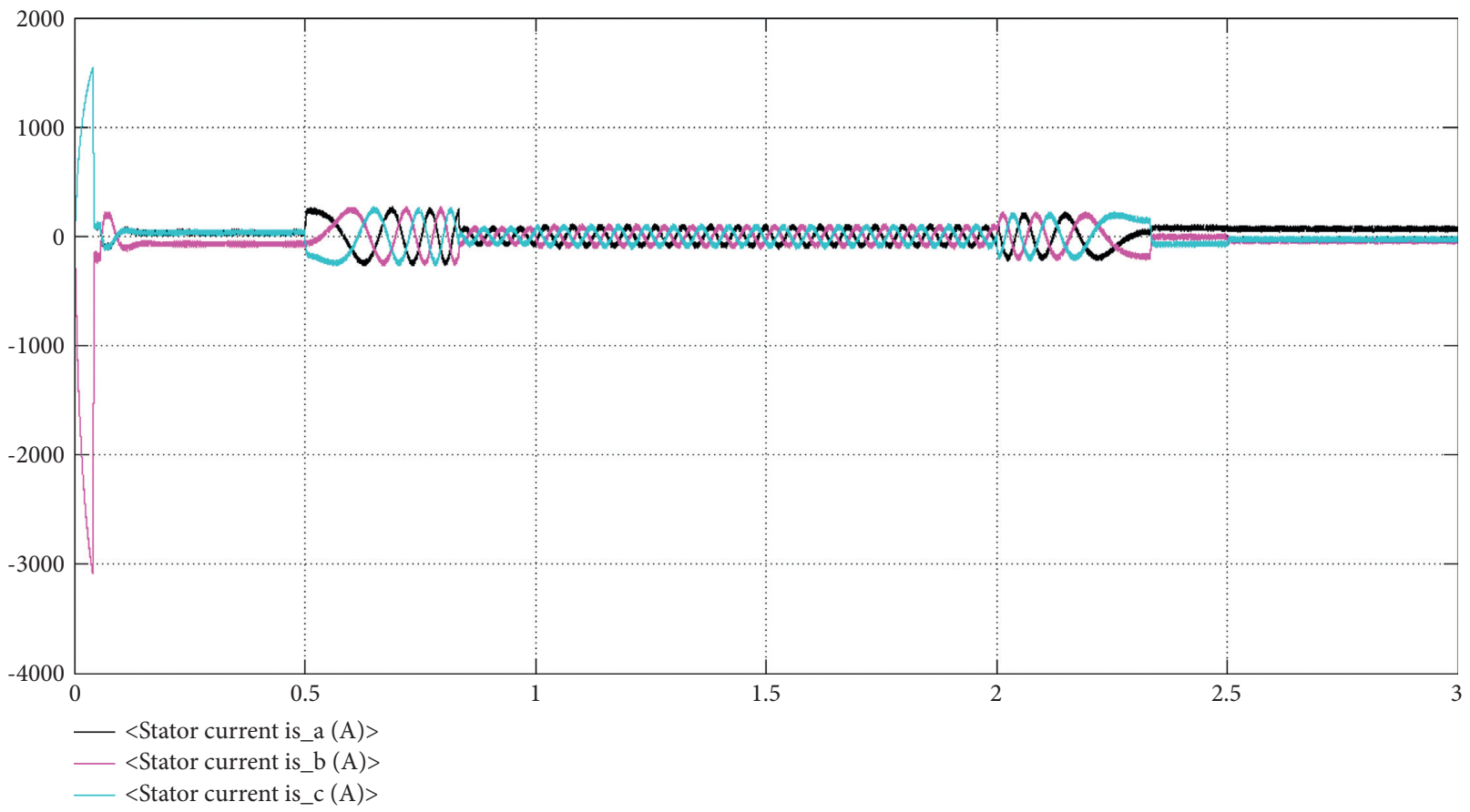

FIgURE 10: Stator current of a three-phase induction motor using the FOC method.

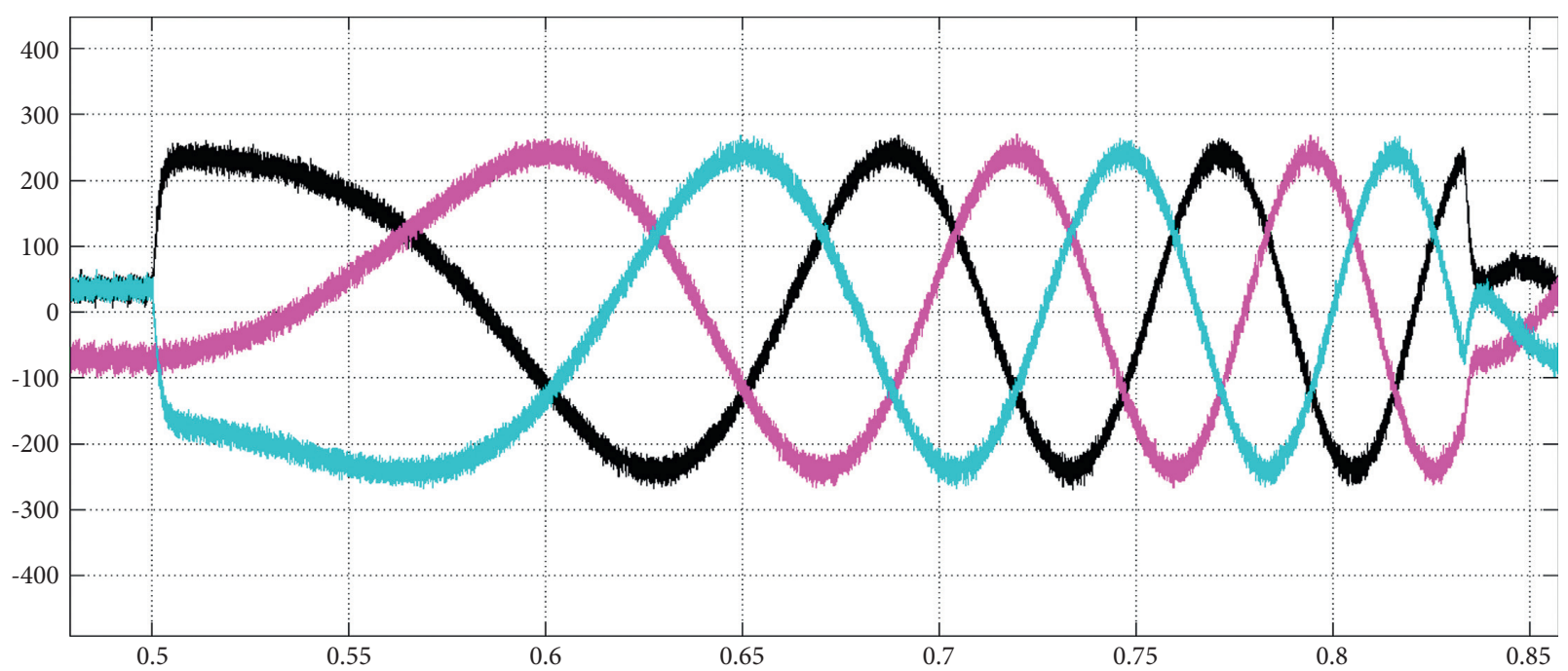

$<$ Stator current is_a $(A)>$

$<$ Stator current is_b (A) $>$

$<$ Stator current is_c (A)>

Figure 11: Stator current during the interval $0.5 \mathrm{~s}$ to $0.85 \mathrm{~s}$. 


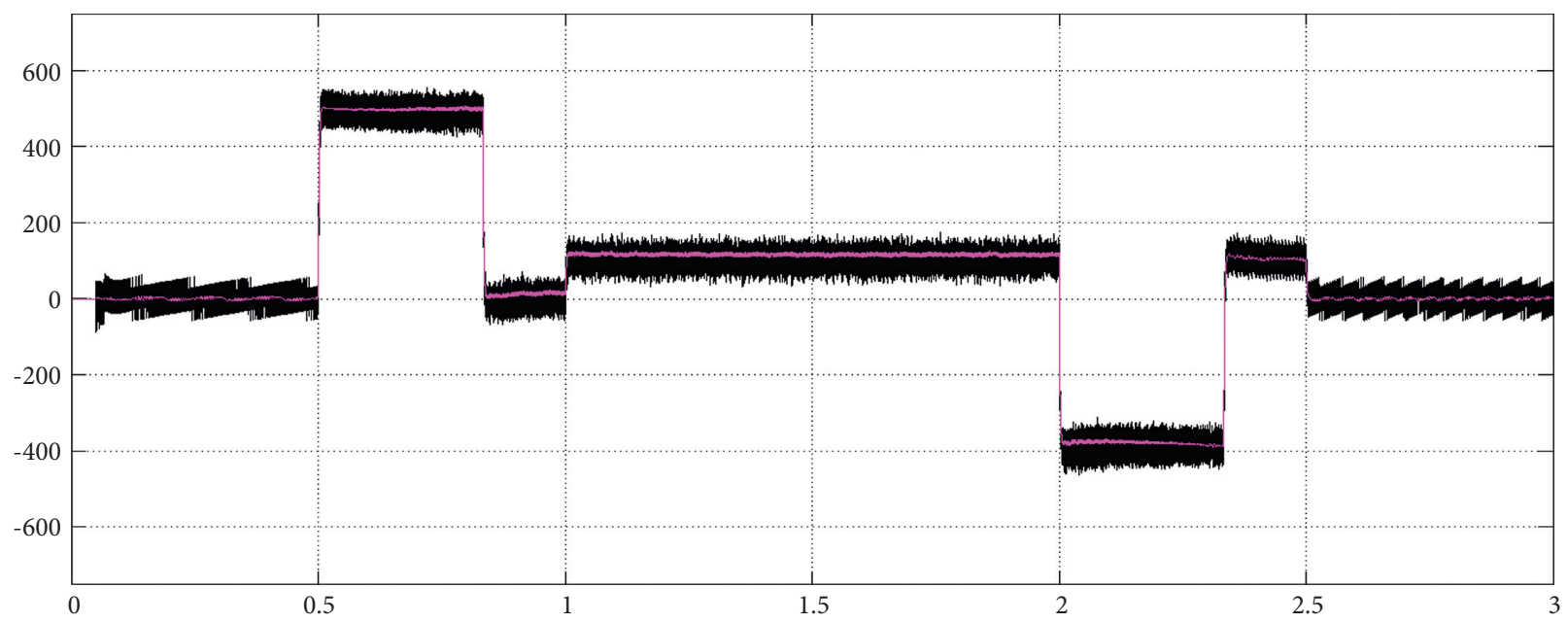

— $<$ Electromagnetic torque $\mathrm{T}$ e $\left(\mathrm{N}^{*} \mathrm{~m}\right)>$

— Torque reference

FIGURE 12: Torque reference and electromagnetic torque of a three-phase induction motor by using the FOC method.

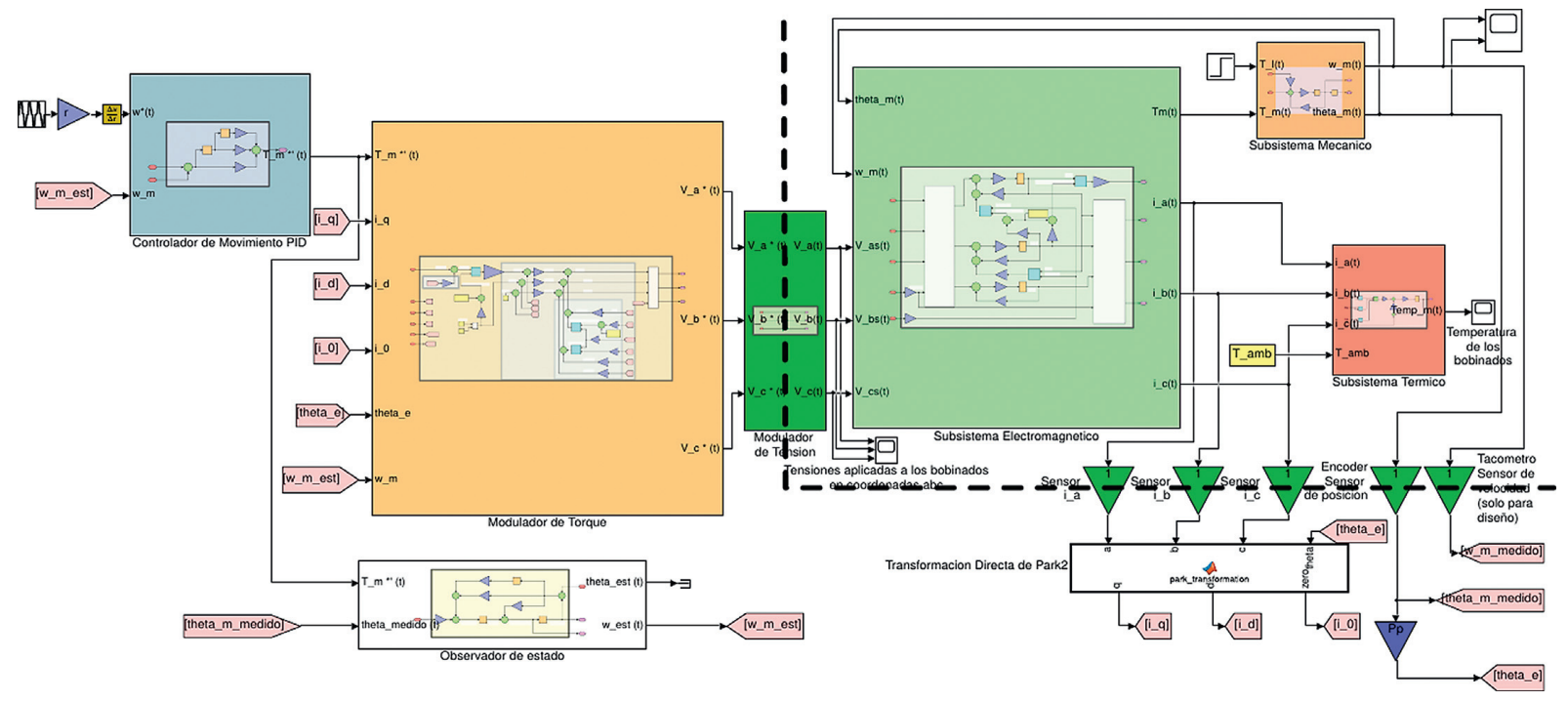

FIGURE 13: Simulink model of the DTC method of induction motor.

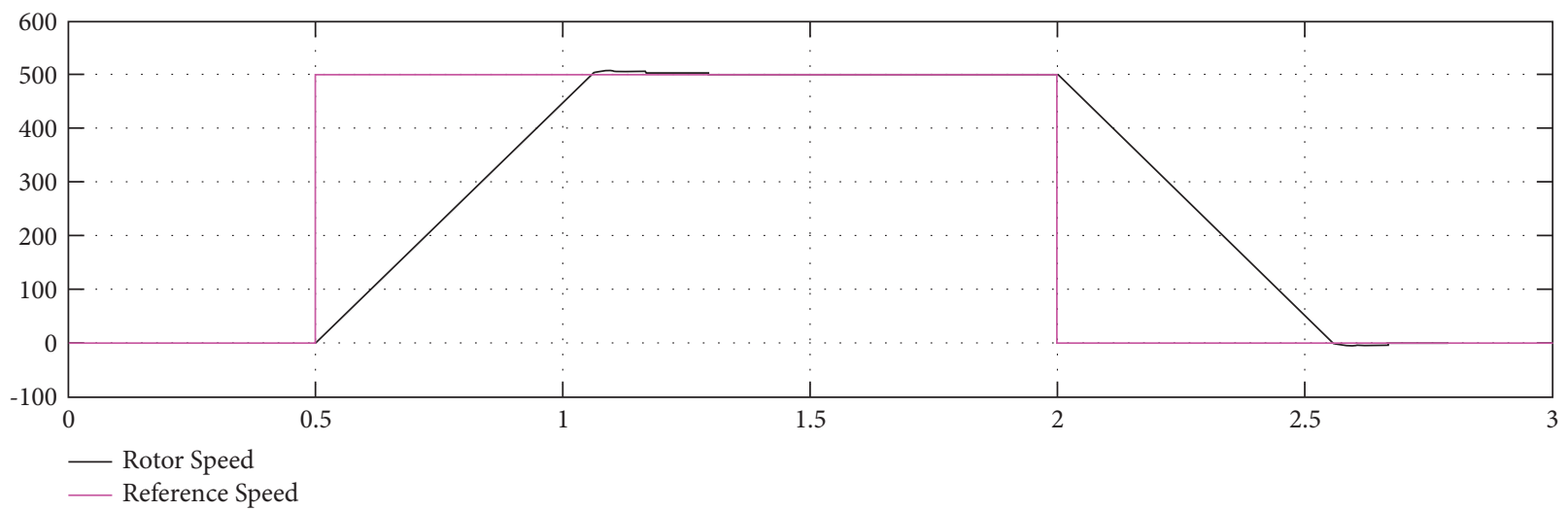

FIgURE 14: Reference speed and rotor speed of a three-phase induction motor using the DTC method. 


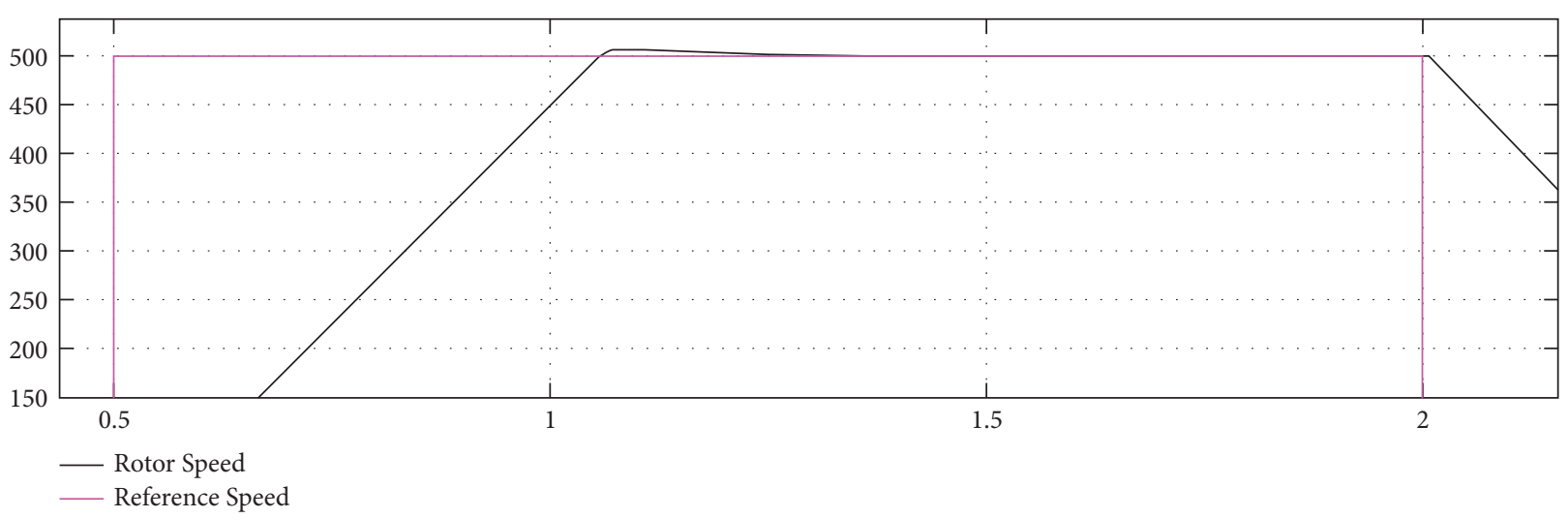

FIgURE 15: Peak overshoot in a three-phase induction motor using the DTC method.

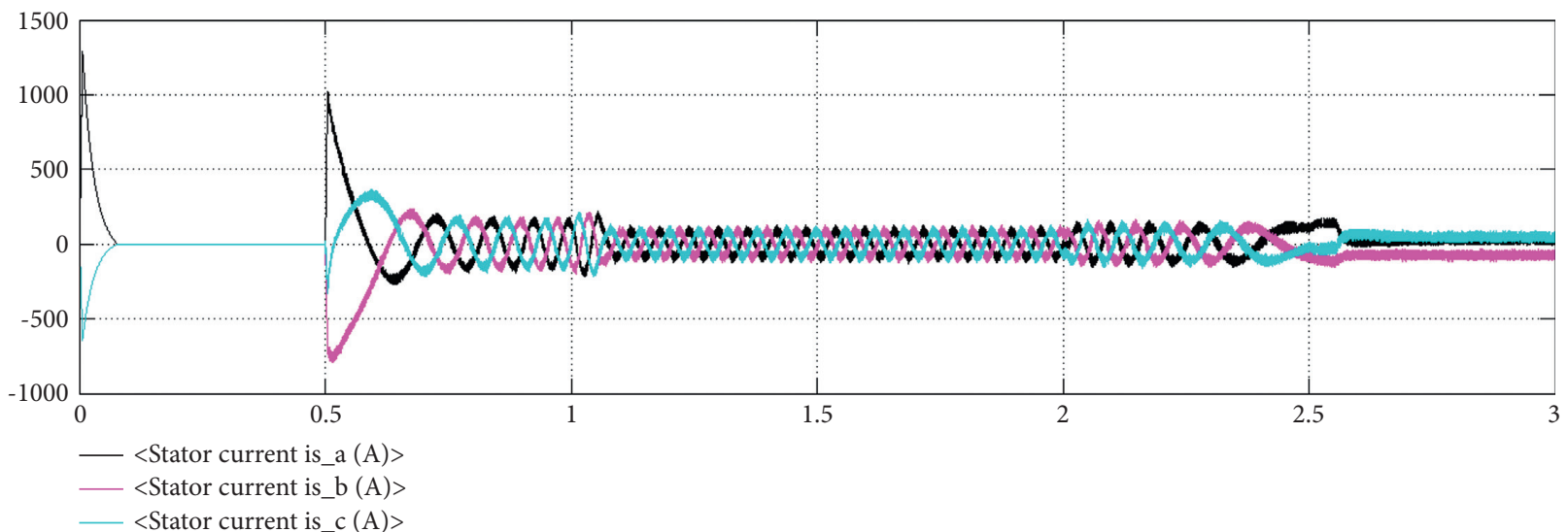

FIgURE 16: Stator current of three-phase induction motor using the DTC method.

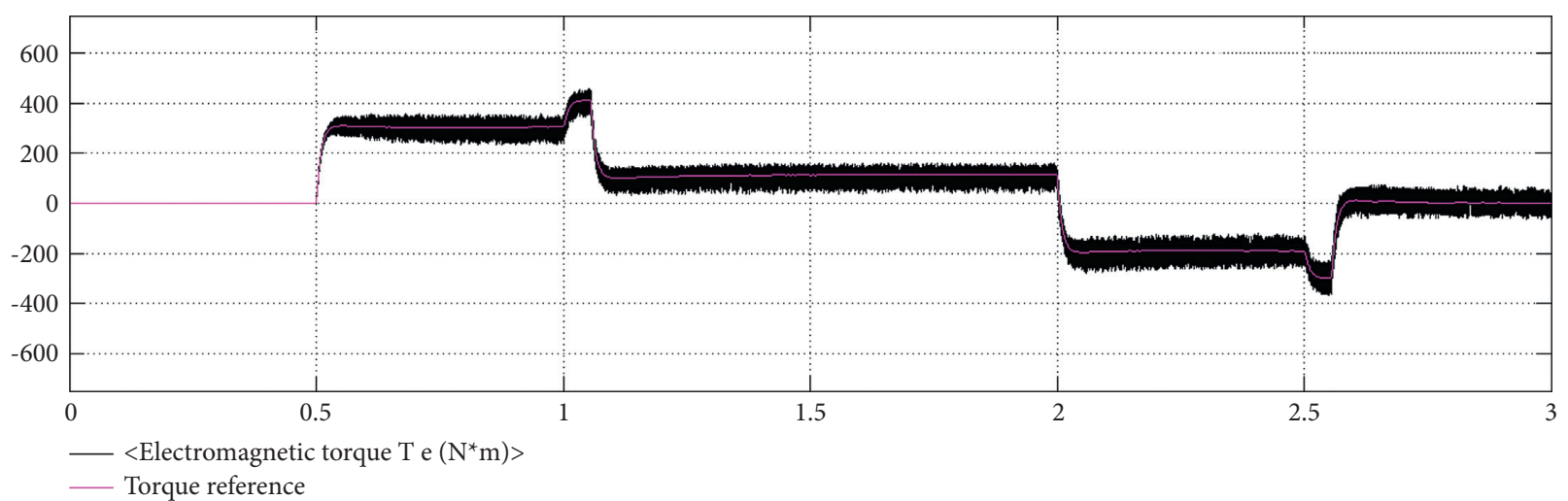

FIgURE 17: Torque reference and electromagnetic torque for a three-phase induction motor using the DTC method.

three-phase induction motor using the DTC method are shown in Figures 14 and 15.

When compared to the FOC approach, the starting current of the stator climbs to a positive maximum of $1200 \mathrm{~A}$ and a negative maximum of $-600 \mathrm{~A}$ for a $200 \mathrm{HP}$ machine, which is shown in Figure 16.

During the speed acceleration at $0.5 \mathrm{~s}$, electromagnetic torque increases to a magnitude of $300 \mathrm{Nm}$ and settles at $100 \mathrm{Nm}$ when the motor achieves a stable speed of $500 \mathrm{rpm}$; these are shown in Figure 17. Table 3 describes the performance evaluation of conventional FOC and DTC with proposed FODPSO-based fuzzy FOC and DTC. From the comparative analysis, the FODPSO-based fuzzy FOC works better than others and gives efficient performance in all parameters. Table 3 represents the performance evaluation of FOC and DTC for a three-phase induction motor. Table 4 represents the comparative analysis of various optimization techniques. 
TABLE 3: The performance evaluation of FOC and DTC for a three-phase induction motor.

\begin{tabular}{|c|c|c|c|c|}
\hline Parameters & FOC & DTC & FODPSO-FLC-based FOC & FODPSO-FLC-based DTC \\
\hline Peak overshoot speed & $501 \mathrm{rpm}$ & $506 \mathrm{rpm}$ & $503 \mathrm{rpm}$ & $504 \mathrm{rpm}$ \\
\hline Settling time & $0.23 \mathrm{~s}$ & $0.28 \mathrm{~s}$ & $0.17 \mathrm{~s}$ & $0.2 \mathrm{~s}$ \\
\hline Rise time & $0.42 \mathrm{~s}$ & $0.61 \mathrm{~s}$ & $0.33 \mathrm{~s}$ & $0.55 \mathrm{~s}$ \\
\hline Fall time & $0.42 \mathrm{~s}$ & $0.61 \mathrm{~s}$ & $0.33 \mathrm{~s}$ & $0.55 \mathrm{~s}$ \\
\hline Torque at $500 \mathrm{rpm}$ & $118 \mathrm{~N} \cdot \mathrm{m}$ & $97 \mathrm{~N} \cdot \mathrm{m}$ & $120 \mathrm{~N} \cdot \mathrm{m}$ & $100 \mathrm{~N} \cdot \mathrm{m}$ \\
\hline Torque during acceleration & $489 \mathrm{~N} \cdot \mathrm{m}$ & $294 \mathrm{~N} \cdot \mathrm{m}$ & $500 \mathrm{~N} \cdot \mathrm{m}$ & $300 \mathrm{~N} \cdot \mathrm{m}$ \\
\hline Torque during deceleration & $-402 \mathrm{~N} \cdot \mathrm{m}$ & $-200 \mathrm{~N} \cdot \mathrm{m}$ & $-400 \mathrm{~N} \cdot \mathrm{m}$ & $-200 \mathrm{~N} \cdot \mathrm{m}$ \\
\hline Starting current (positive peak) & $1535 \mathrm{~A}$ & $1196 \mathrm{~A}$ & $1540 \mathrm{~A}$ & $1200 \mathrm{~A}$ \\
\hline Starting current (negative peak) & $-3050 \mathrm{~A}$ & $-600 \mathrm{~A}$ & $-3050 \mathrm{~A}$ & $-600 \mathrm{~A}$ \\
\hline Stator current at $500 \mathrm{rpm}$ & $100 \mathrm{~A}$ & $100 \mathrm{~A}$ & $100 \mathrm{~A}$ & $100 \mathrm{~A}$ \\
\hline
\end{tabular}

TABLE 4: A comparative analysis of various optimization techniques.

\begin{tabular}{|c|c|c|c|c|}
\hline Different optimization techniques & Rise time & Fitness function & Switching loss & Algorithm complexity \\
\hline DTC-conventional & High & High & High & Simple \\
\hline FOC-conventional & High & High & High & Simple \\
\hline DTC-GA & Medium & Moderate & Medium & Complex \\
\hline FOC-GA & Medium & Moderate & Medium & Complex \\
\hline DTC-BOA & Medium & Moderate & High & Good \\
\hline DTC-BOA & Medium & Moderate & High & Good \\
\hline FOC-fuzzy & Low & Low & Low & More complex \\
\hline DTC-fuzzy & Low & Low & Low & More complex \\
\hline DTC-FODPSO & Low & Low & Low & Good \\
\hline FOC-FODPSO & Very low & Low & Low & Good \\
\hline
\end{tabular}
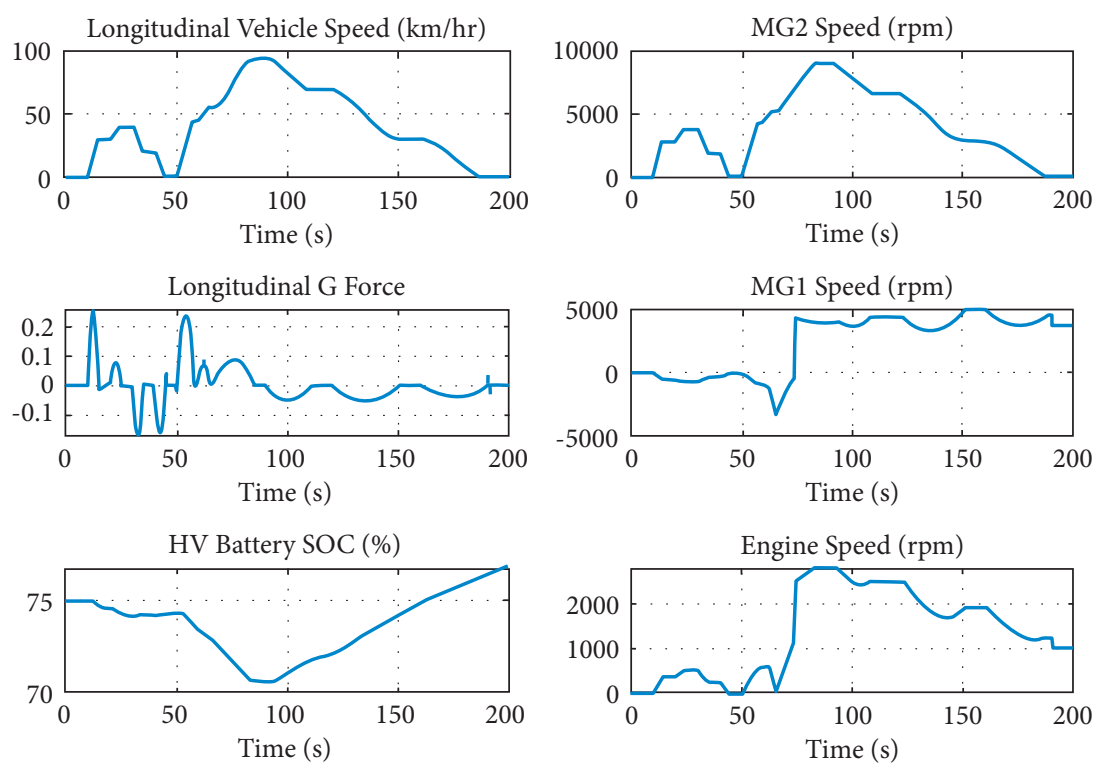

Figure 18: Overall performance of the controllers.

Table 4 shows the comparative analysis of various optimization techniques used in the induction motor controller. It compares the rise time, fitness function, switching loss, and algorithm complication of different optimization techniques.

Figure 18 represents the controller performance. The proposed method of FODPSO-based fuzzy logic control technique performs better than other optimization techniques.

\section{Conclusion}

An induction motor of 200 horsepower was modeled using MATLAB-Simulink, which is utilized to create a model of field-oriented control and direct torque control techniques for the motor. When comparing the DTC approach to the FOC method, it has been discovered that the DTC method produces superior outcomes. This paper proposes an optimization strategy for controlling the FOC and DTC methods 
that is based on FODPSO. It is necessary to do a performance analysis of both strategies in order to compare their results. The FODPSO-based FOC outperforms both the DTC technique and other traditional methods in terms of performance. The DTC technique requires less starting current and less torque for the same speed since the starting current and torque requirements are lower in the DTC method.

Energy efficiency optimization is very important not just for electrical systems but for all systems in order to be useful in terms of money and also in terms of lowering global warming emissions. Through the use of optimum control and design methodologies, this study provided a comprehensive overview of recent achievements in the area of efficiency optimization of three-phase induction motors. It included both the broad techniques of loss model control and the search control that were discussed in detail in the previous section. Optimization of design adjustments in materials and structure in order to maximize the efficiency of the motor is covered by the term "optimal design." These techniques include artificial neural networks, fuzzy logic, expert systems, and nature-inspired algorithms. Other techniques such as genetic algorithms, differential evolution, evolutionary programming, evolutionary strategy, and simulated annealing were also included in this paper's future work of optimization.

\section{Data Availability}

The data that support the findings of this study are available on request from the corresponding author.

\section{Conflicts of Interest}

The authors declare that they have no conflicts of interest.

\section{References}

[1] T. Rekioua and D. Rekioua, "Direct torque control strategy of permanent magnet synchronous machines," in Proceedings of the Proc. BPTCP, June 2003.

[2] N. P. Gupta and P. Gupta, "Performance analysis of direct torque control of PMSM drive using SVPWM-inverter," in Proceedings of the Proc. IICPE, December 2012.

[3] I. Takahashi and T. Noguchi, "A new quick-response and high-efficiency control strategy of an induction motor," IEEE Transactions on Industry Applications, vol. IA-22, no. 5, pp. 820-827, 1986.

[4] H. Maghfiroh, J. S. Saputro, F. Adriyanto, A. Sujono, and R. L. Lambang, "Performance evaluation of fuzzy-PID in speed control of three phase induction motor," IOP Conference Series: Materials Science and Engineering, vol. 1096, no. 1, Article ID 012071, 2021.

[5] M. Abassi, A. Khlaief, O. Saadaoui, A. Chaari, and M. Boussak, "Performance analysis of FOC and DTC for PMSM drives using SVPWM technique," in Proceedings of the Proc. ICSTACCE, pp. 228-233, IEEE, Monastir, Tunisia, December 2015.

[6] U. Baader, M. Depenbrock, and G. Gierse, "Direct self control (DSC) of inverter-fed induction machine: a basis for speed control without speed measurement," IEEE Transactions on Industry Applications, vol. 28, no. 3, pp. 581-588, 1992.

[7] B. K. Bose, "Power electronics-a technology review," Proceedings of the IEEE, vol. 80, no. 8, pp. 1303-1334, 1992.

[8] J. B. Marshel and C. K. Babulal, "Market power analysis in power systems using PSO based must run indices," International Transactions on Electrical Energy Systems, vol. 30, no. 12, Article ID e12675, 2020.

[9] V. J. Bobin and M. Beno, "Performance evaluation of a PMSM with fuzzy controller employing armature voltage control scheme," in Proceedings of the ProcICEETS, pp. 1-8, IEEE, Tamilnadu, India, April 2018.

[10] J. N. Nash, "Direct torque control, induction motor vector control without an encoder," IEEE Transactions on Industry Applications, vol. 33, no. 2, pp. 333-341, 1997.

[11] H. L. Huy, "Comparison of field-oriented control and direct torque control for induction motor drives," in Proceedings of the Proc. IAC, October1999.

[12] S. Vaez-Zadeh and E. Jalali, "Combined vector control and direct torque control method for high performance induction motor drives," Energy Conversion and Management, vol. 48, no. 12, pp. 3095-3101, 2007.

[13] B. Kabalan, E. Vinot, C. Yuan, R. Trigui, C. Dumand, and T. E. Hajji, "Efficiency improvement of a series-parallel hybrid electric powertrain by topology modification," IEEE Transactions on Vehicular Technology, vol. 68, no. 12, pp. 1152311531, 2019.

[14] A. P. Vora, X. Jin, V. Hoshing et al., "Design-space exploration of series plug-in hybrid electric vehicles for mediumduty truck applications in a total cost-of-ownership framework," Applied Energy, vol. 202, pp. 662-672, 2017.

[15] F. Lei, Y. Bai, W. Zhu, and J. Liu, "A novel approach for electric powertrain optimization considering vehicle power performance, energy consumption and ride comfort," Energy, vol. 167, pp. 1040-1050, 2019.

[16] B. Sivasankari, A. Ahilan, R. Jothin, and A. Jasmine Gnana Malar, "Reliable N sleep shuffled phase damping design for ground bouncing noise mitigation," Microelectronics Reliability, vol. 88-90, pp. 1316-1321, 2018.

[17] A. Jasmine Gnana Malar, C. GnanaSaravanan, and A. G. Saravanan, "Iot based sustainable wind green energy for smart cites using fuzzy logic based fractional order darwinian particle swarm optimization," Measurement, vol. 166, Article ID 108208, 2020.

[18] V. Roy, P. K. Shukla, A. K. Gupta, V. Goel, P. K. Shukla, and S. Shukla, "Taxonomy on EEG artifacts removal methods, issues, and healthcare applications," Journal of Organizational and End User Computing, vol. 33, no. 1, pp. 19-46, 2021.

[19] D. Singh, J. Singh, and A. Chhabra, "High availability of clouds: failoverstrategies for cloud computing using integrated calgorithms," in Proceedings of the 2012 International Conference on Communication Systems and Network Technologies, Rajkot, India, May 2012.

[20] N. K. Rathore, N. K. Jain, P. K. Shukla, U. S. Rawat, and R. Dubey, "Image forgery detection using singular value decomposition with some attacks," National Academy Science Letters, vol. 44, pp. 331-338, 2021.

[21] D. Singh and V. Kumar, "A comprehensive review of computational dehazing techniques," Archives of Computational Methods in Engineering, vol. 26, no. 5, pp. 1395-1413, 2019.

[22] S. Pandit, P. K. Shukla, A. Tiwari, P. K. Shukla, and R. Dubey, "Review of video compression techniques based on fractal transform function and swarm intelligence," International 
Journal of Modern Physics B, vol. 34, no. 8, Article ID 2050061, 2020.

[23] G. Khambra and P. Shukla, "Novel machine learning applications on fly ash based concrete: an overview," Materials Today Proceedings, pp. 2214-7853, 2021.

[24] P. Bedi, S. B. Goyal, J. Kumar, and S. Choudhary, "Smart automobile health monitoring system," in Multimedia Technologies in the Internet of Things Environment, R. Kumar, R. Sharma, and P. K. Pattnaik, Eds., Springer, Berlin, Germany, Springer, 2022 Studies in Big Data.

[25] P. K. Shukla, J. KaurSandhu, A. Ahirwar, D. Ghai, P. Maheshwary, and P. K. Shukla, "Multiobjective genetic algorithm and convolutional neural network based COVID19 identification in chest X-ray images," Mathematical Problems in Engineering, vol. 2021, Article ID 7804540, 9 pages, 2021. 